\title{
FÓRUM
}

Recebido em 08.08.2013. Aprovado em 16.12.2014

Este artigo tem coautoria de membro do Corpo Editorial Científico da RAE; foi avaliado em double blind review, com isenção e independência.

Editores Científicos: Ernesto R. Gantman, Helà Yousfi e Rafael Alcadipani

DOI: http://dx.doi.org/10.1590/So034-759020150205

\section{O COTIDIANO E A HISTÓRIA: CONSTRUINDO NOVOS OLHARES NA ADMINISTRAÇÃO}

\author{
Everyday life and history: constructing new perspectives in Management \\ Lo cotidiano y la historia: construyendo nuevos enfoques en la Administración
}

\begin{abstract}
AMON BARROS
amon.barros@fgv.br

Professor da Fundação Getulio Vargas, Escola de Administração de Empresas de São Paulo - São Paulo - SP, Brasil
\end{abstract}

\section{ALEXANDRE DE PÁDUA CARRIERI}

aguiar.paduacarrieri@terra.com.br Professor da Universidade Federal de Minas Gerais, Faculdade de Ciências Econômicas - Belo Horizonte - MG Brasil

\section{RESUMO}

O objetivo deste artigo é discutir as possíveis contribuições de estudos que fazem confluir história e cotidiano para a construção de novos olhares sobre a Administração. Para atender a esse objetivo, debatemos a aproximação entre a Administração e a história e os estudos sobre o cotidiano como opção para se produzirem olhares alternativos dentro da Administração. Concluímos reiterando que a construção desses diálogos pode abrir trilhas interessantes para o desenvolvimento de conhecimentos autorrefletidos e que estejam posicionados política, social e geograficamente.

PALAVRAS-CHAVE | Administração, história, cotidiano, gestão ordinária, americanismo.

\section{ABSTRACT}

The purpose of this article is to discuss the possible contributions of studies that combine history and everyday life to build new perspectives about Management. To achieve this goal, we discuss the association of Management, history, and studies about everyday life as an option to produce alternative perspectives within Management. We conclude by reiterating that the construction of these dialogues can open interesting paths to the development of self-reflective knowledge that are politically, socially, and geographically positioned.

KEYWORDS / Management, history, everyday life, ordinary management, Americanism.

\section{RESUMEN}

El objetivo de este artículo es discutir las posibles contribuciones de estudios que hacen confluir historia y cotidiano para la construcción de nuevos enfoques sobre la Administración. Para cumplir ese objetivo, debatimos la aproximación entre la Administración y la historia y los estudios sobre lo cotidiano como una opción para producir enfoques alternativos dentro de la Administración. Concluimos reiterando que la construcción de esos diálogos puede abrir caminos interesantes para el desarrollo de conocimientos auto-reflejados y que estén posicionados política, social y geográficamente.

PALABRAS-CLAVE / Administración, historia, cotidiano, gestión ordinaria, americanismo. 


\section{CONSIDERAÇÕES INICIAIS}

O objetivo deste trabalho é discutir como estudos que usem, de maneira dialógica, a história e o cotidiano podem possibilitar o aparecimento de outros olhares sobre os saberes e práticas na Administração, especialmente nos Estudos Organizacionais. Salientamos a importância das singularidades na construção das teorias, ao mesmo tempo que apontamos a elaboração de análises situadas no tempo e no espaço, bem como a ênfase nos "esquecidos" da Administração, como um contraponto às visões dominantes no campo, constituído majoritariamente por teorias que foram elaboradas com base na realidade dos Estados Unidos da América (EUA).

Acreditamos ser possível questionar a hegemonia estadunidense, acerca de quais são os saberes considerados legítimos. Entendemos por hegemonia a supremacia de um conjunto de ideias sobre outras, numa relação dialógica que estabelece transformações nos discursos que se relacionam e estabelecem o que é considerado centro e, por contraposição, periferia. No caso em tela, essa hegemonia pode ser chamada de "americanismo", compreendido como a posição privilegiada de conhecimentos de estadunidense ou, de modo mais abrangente, anglo-saxão em relação àqueles produzidos em outras regiões (e.g. Frenkel, 2009), que afeta desde as narrativas sobre a formação da Administração - que tendem a colocar os EUA no centro e outros países nas margens e de maneira subordinada - até à compreensão das práticas desenvolvidas em outras partes do mundo (ver Frenkel \& Shenhav, 2003, 2006; Jacques, 1996).

Nesse sentido, é importante descolonizar o olhar do pesquisador (Alcadipani \& Rosa, 2010), abrindo espaço para que as construções teóricas elaboradas na periferia do campo acadêmico possam ser destacadas (ver Alcadipani, Khan, Gantman, \& Nkomo, 2012). Diferentes epistemologias podem ser consideradas para compreender o social, o cultural e o histórico, reconhecendo que há, na relação de hegemonia estabelecida pelos saberes "americanos", certas construções que se impõem, criando discursos que simplificam o que é considerado "outro" (e.g. Ibarra-Colado, 2006; Said, 1990). Esse "outro", constantemente relegado ao campo do "exótico", é reconhecido mais como objeto de pesquisa do que como polo capaz de produzir saberes legitimáveis (Alcadipani \& Rosa, 2010). Um exemplo é o trabalho de Murphy e Zhu (2012), que aponta a dificuldade de pesquisadores das periferias em publicar nos periódicos que se dizem “internacionais", especialmente aqueles que vêm de países que não têm o inglês como primeira língua.

Como alternativa para contornar a hegemonia anglo-saxã na produção e distribuição de conhecimentos, apontamos a confluência de duas abordagens. A primeira é a opção por estu- dos calcados na história. Acrescemos a esses as potencialidades de se partir do cotidiano das pessoas comuns, dos praticantes, como forma de abrir espaço para conhecimentos que são vivificados pelas práticas das pessoas: diversos sujeitos que exercem práticas administrativas e não têm suas ações reconhecidas. Pensamos especialmente nos administradores de médios, pequenos e micronegócios, formais ou informais, familiares e não familiares, que praticam uma gestão que poderíamos chamar de “ordinária”, do dia a dia - noção em consonância com a ideia de cultura ordinária delineada por Certeau (1994).

Essa gestão ordinária, embora tenha pontos de contato com a Administração como discurso estruturado, não é diretamente moldada por ela. Ao mesmo tempo, ela é a gestão que não se adéqua totalmente e que, na verdade, questiona na prática a universalidade da Administração hegemônica e de suas lógicas de maximização de resultados e orientação racional das ações dos sujeitos, ainda que recorrentemente estabeleça trocas com esses discursos mais estruturados. É aí que, em geral, se situa o "administrador ordinário", o pequeno comerciante que faz cálculos de cabeça e desconhece os conceitos da matemática financeira. Considere-se, ainda, o conhecimento dos trabalhadores, que muitas vezes são ignorados nas narrativas da e sobre a Administração, mas que obviamente refletem e têm um ponto de vista sobre o contexto no qual se inserem, como discutido por Holanda (2011).

Visando discutir a temática estabelecida e atender aos objetivos propostos, o texto foi dividido em quatro seções além da introdução. Na primeira, contextualizamos o campo de Estudos Organizacionais, enfatizando como a hegemonia dos saberes anglo-saxônicos estabelece um quadro de legitimidade no acampo, relegando às margens saberes "alternativos". Em seguida, discutimos a aproximação entre a Administração e a história, apresentando e tecendo considerações sobre como a confluência entre essas áreas permite a construção de novos olhares na Administração. Em sequência, estabelecemos uma argumentação sobre o cotidiano como campo analítico, mostrando que o enfoque nos particulares pode contrapor e enriquecer as narrativas dominantes na Administração, em especial quando aliado às discussões sobre a história. Por fim, tecemos as considerações finais, momento no qual buscamos consolidar o debate realizado.

\section{CONTEXTO DA ADMINISTRAÇÃO E DOS ESTUDOS ORGANIZACIONAIS}

Ao falar da Administração e dos Estudos Organizacionais, é necessário abordar tanto os desenvolvimentos das discussões 
acadêmicas quanto o contexto no qual se dão. Cada saber constitui-se numa complicada relação com o contexto, e é também fruto de possibilidades abertas pela conjuntura de forças num dado momento. Nesse sentido, é importante considerar que as dinâmicas de relações de dominação ao estilo centro-periferia, nos moldes do que discute Said (1990), permeiam a lógica de construção de saberes nesse campo.

Ao clamarmos pela valorização do saber construído às margens do que é elaborado nos EUA, sustentamos a necessidade de se abrir espaço para construções não hegemônicas, produzidas nas periferias, como as abordagens pós-colonialistas ou descolonialistas e a teoria da dependência (Mignolo, 2007), por exemplo. Não se trata de buscar uma improvável Administração livre de influências do campo hegemônico, mas de construir um espaço para pensar a área e suas práticas a partir de perspectivas alternativas, como propõem, por exemplo, Alcadipani et al. (2012).

Pensar a Administração que fica à margem do centro - do conhecimento, da economia e da geopolítica mundial - é considerar que essa relação de hegemonia não é mecânica e que os saberes relacionam-se e, dessa forma, transformam-se (e.g. Frenkel \& Shenhav, 2003). A Administração constrói-se como discurso que toma forma pela subordinação de certas perspectivas em relação a outras (Alcadipani \& Rosa, 2011; Ibarra-Colado, 2006). Assim, concordamos com Candiotto (2010), que, baseando-se em Foucault, entende que os sistemas considerados racionais nas Ciências Humanas são a consolidação de sistemas excludentes de poder que aceitam certas verdades enquanto excluem diversos saberes concorrentes na formação de certo discurso (Foucault, 2009).

Como discurso, não se assenta apenas nas "coisas como elas são" nem é apenas “ilusão". Para além de ser "verdadeiro", tem "efeito de verdade" e, ao incluir a realidade em sua representação, contribui para moldá-la, reafirmá-la e (re)construí-la, conforme aponta Foucault (2009). Tal apontamento é compartilhado por Barley e Kunda (1992), que consideram que as teorias, por vezes, “criam realidades”, engendrando discursivamente os lugares que devem ocupar, entre outros, "o gerente", “o funcionário”, “o consultor” e "a empresa”.

Os discursos são estabelecidos em relação às práticas: "a autonomia do discurso e sua especificidade não lhe dão, por isso, um status de pura idealidade e de total independência histórica” (Foucault, 2009, p. 185-186). Assim, afirmar um desligamento das teorias com as práticas é ignorar que o próprio fazer acadêmico é uma prática que produz seus efeitos sobre outras práticas. Teoria e prática não guardam uma relação especular entre si e, tampouco, uma relação linear de determinação de uma sobre a outra. Haverá sempre mediações entre ambas que fazem com que os discursos produzidos por uns e outros enunciadores tenham efeitos que se inscrevem em uma rede relacional, permeada por disputas de poder. Nesse sentido, a posição (tanto metafórica quanto geográfica) de onde se fala adquire importância, como se discutirá adiante e como apontam, por exemplo, Xavier, Barros, Cruz e Carrieri (2012).

A supremacia do capitalismo liberal coloca que há maneiras ótimas de se gerenciarem as organizações, calcadas nas elaborações que são hegemônicas nos EUA, o principal ator geopolítico da contemporaneidade, como apontam Alcadipani e Rosa (2011) e Grey (2010). A Administração à americana constituiu-se especialmente a partir da visão estabelecida no contexto da Guerra Fria, momento em que a Administração se consolidava como discurso científico e que Runté e Mills (2006) chamaram de "momento formativo". Naquele momento, começaram a ser estabelecidas as posições em relação aos sindicatos (Frenkel \& Shenhav, 2003, 2006), ao trabalhador (sua cor e sua posição social) e o papel do indivíduo (Grant \& Mills, 2006), tendo a mulher numa posição de subordinação (Runté \& Mills, 2006). A administração era vista como um produto "americano", uma sociedade que não teria conflitos internos, ao mesmo tempo que serve como instrumento contra o comunismo (Jacques, 1996; Kelley, Mills, \& Cooke, 2009). Concomitantemente, práticas e instituições, como as escolas de negócio, os programas de MBA, as consultorias e o lugar de mando legitimado do gestor reiteram o papel dos EUA na constituição do campo da Administração (Jacques, 1996; Locke, 1996).

Outro elemento para se entender a hegemonia dos EUA é a desproporcionalidade em relação ao número de editores e de autores oriundos daquele país em periódicos que se pretendem de "nível mundial”, marginalizando mesmo pesquisadores europeus (Grey, 2010; Meyer \& Boxenbaum, 2010; Murphy \& Zhu, 2012). Epistemologias alternativas são deixadas de lado nessas publicações (Ibarra-Colado, 2006), e, como mostram Murphy e Zhu (2012), o conhecimento produzido por autores de fora dos países anglo-saxões não é representado nos principais periódicos da área. Tal estudo reitera a posição Meyer e Boxenbaum (2010), que apontam que a América do Sul e a África são mais sujeitas à sub-representação em periódicos "de nível mundial” do que autores de países da Europa ("ocidental”), mas que todos esses sofrem com a barreira da língua. Grey (2010) também nota que atualmente não há espaço para trabalhos que coloquem em evidência estudos produzidos em outros lugares que não sejam os países centrais: a Europa central e, principalmente, os EUA.

Para Alcadipani e Rosa (2010, p. 372), as teorias administrativas e a organização da academia bloqueiam o desenvolvimento de histórias locais sobre a gestão e têm como base: 
um tipo de "racismo epistêmico" que segrega

e dispensa o conhecimento produzido fora de suas fronteiras sob o argumento de ele ser particularístico, incapaz de alcançar a "universalidade" dos modelos de gestão.

Ainda, conforme esses autores, deve-se alterar esse pensamento e:

[...] assumir a produção do conhecimento científico a partir da "pluriversalidade", em que diversas epistemologias são consideradas e potencialmente válidas para compreender o social. Potencialmente porque a descolonização ainda enfrenta o obstáculo das hierarquias coloniais que olham para o Sul como Outro lugar, Outra história, Outra cultura, habitada por Outros sujeitos (Alcadipani \& Rosa, 2010, p. 372).

Ibarra-Colado (2006) e Jacques (1996), entre outros, apontam a naturalização do saber administrativo, que o retira do contexto sócio-histórico sua origem. Para eles, as teorias administrativas do século XX fazem um duplo movimento de construção da realidade organizacional e de ornamentação dessa realidade sob o manto da racionalidade, que exclui outros modos de organizar que não aquele fundado no cálculo utilitarista. Para Mattos (2009), as teorias “tradicionais" (estadunidenses) da Administração constroem discursos de um conhecimento tido como puro ou neutro (restrito ao racional), absoluto e que se quer universal (e se torna excludente de outros saberes concorrentes). Esses discursos de matiz estadunidense triunfaram política e economicamente em parte por meio das tecnologias de gestão, que estabelecem modos de fazer supostamente neutros (Jacques, 1996), embora caiba ressaltar, como se discutirá adiante, quando tratarmos do cotidiano, que não existe a dominação completa.

Como afirma Benjamin (2006, p. 51) "saber é posse", enquanto para Foucault (1987) saber é poder. Assim, a Administração, como disciplina/saber, confere posse de um conhecimento que se quer universal, pois é capaz de dar respostas aos mais diversos problemas em quaisquer organizações. Ao mesmo tempo, poucos têm legitimidade para produzir e distribuir esses conhecimentos. A gestão dita "universal" deve ser vista como um espaço de saber-poder e de disputas, conforme mostram Clegg e Hardy (1996), de ressignificações.

$\mathrm{Na}$ mesma linha, Rowlinson, Jacques e Booth (2009) afirmam que boa parte do conhecimento em Administração é estabelecido numa chave "universalista" e "presentista" (presentist). Universalista, porque a teoria é elaborada como se fosse aplicável a organizações de qualquer sociedade, a qualquer momento. Presentista, pois caracteriza as pesquisas que são narradas como se acontecessem sempre no presente. Assim, contexto e temporalidade são ignorados, produzindo conceitos genéricos, a ponto de serem utilizados para analisar (e solucionar) problemas de qualquer lugar ou momento histórico, ao mesmo tempo que o que diferiria a teoria hoje da que a precedeu seria seu aprimoramento paulatino decorrente do desenvolvimento da "ciência". É essa chave de construção de argumentos que permite, por exemplo, que se identifique a "Administração" na construção das pirâmides, desconsiderando todos os processos históricos que inevitavelmente transformaram as relações sociais, as relações de trabalho, as formas de monitoramento e seus objetivos, entre outros aspectos.

Mattos (2009) aponta que, na Administração, como campo de saber-fazer, se acredita que as teorias se oferecem em feixes, ou totalidades, organizados. Para o autor, historicamente, um conjunto de teorias que são estruturalmente semelhantes surge como uma articulação de uma condição histórica específica. Nesse sentido, quando autores buscam o estabelecimento de um paradigma que dê conta de toda a multiplicidade da área, como Pfeffer (1993), ou ignoram esse aspecto conjuntural que permite a emergência de certas teorias que são ligadas ao contexto em que emergem, ou desejam reforçar exatamente essa posição de dominância.

Para superar essas características que legitimam a ciência administrativa, mas enfraquecem seu potencial de explicar as nuances da realidade, defendemos, juntamente com outros autores (e.g. Clark \& Rowlinson, 2004; Rowlinson et al., 2009; Vizeu, 2010), a utilização da história como forma de enriquecer os debates em Administração (discutida na próxima seção) e, especialmente, da história associada ao cotidiano (discutida subsequentemente).

\section{A APROXIMAÇÃO ENTRE HISTÓRIA E ESTUDOS ORGANIZACIONAIS}

A aproximação entre a história e a Administração não é um evento isolado no âmbito das disciplinas acadêmicas. É importante frisar as mudanças que afetaram o campo da história, como lembra Burke (1992), após a influência causada pelos debates ensejados pela Escola dos Annales (Burke, 2010; Novais \& Silva, 2011), que ampliaram as fronteiras da disciplina. Burke (1992) atesta que as novas formas de fazer história fizeram emergir questionamentos que ampliaram os horizontes dos problemas tratados pela disciplina. Ao mesmo tempo, Guarinello (2004) aponta para o desconforto com a história cen- 
tralizada na Europa e em objetos como nações e Estados, que perderam espaço para perspectivas, consideram atores antes ignorados e concentram-se em estudos de caso, na micro-história e na história do cotidiano.

É o caso, por exemplo, do trabalho de Ginzburg (1989), que, partindo dos documentos produzidos para o julgamento de um moleiro no século XVI, questiona a relação mecânica de determinação da cultura erudita sobre a cultura popular, defendendo uma relação dialógica e complexa. Ainda que específicas, as reflexões elaboradas com base nesse trabalho permitem pensar em como os "gestores ordinários" relacionam e relacionaram as suas práticas à Administração acadêmica e estadunidense que desembarcou no Brasil de maneira mais intensa a partir da década de 1950, como discutem Barros e Carrieri (2013) e Alcadipani e Bertero (2012).

Conforme Burke (1992), essa mudança de foco de análise levou à expansão das fontes consultadas, como as atas do julgamento das quais se valeu Ginzburg (1989). Isso contribuiu para a chancela de novos elementos como passíveis de análise histórica, com os pesquisadores voltando-se à memória das pessoas, aos registros audiovisuais e ao uso da estatística, visando complementar ou substituir pesquisas realizadas com documentos (Burke, 1992). Aliás, a visão crítica ao uso de documentos como fontes foi influenciada pelas ideias de Foucault (2009), que defende que documento é monumento. Também pela valorização de outras fontes, inclusive para que aquilo que não era documentado pudesse ser estudado, já que toda atividade humana pode ser fonte de história (Burke, 1992; Goff, 2003).

Como ressalta Burke (1992, 2010), os questionamentos à supremacia da história política sobre outras construções possibilitaram a abertura do diálogo da história com diversas disciplinas, especialmente a sociologia e a economia. Novais e Silva (2011) apontam que a nova história, entendida como a inflexão na disciplina provocada pela Escola dos Annales, já se institucionalizou como "história", ainda que haja disputas em relação a qual das três gerações dos Annales dever ser considerada a "nova" (cf. Burke, 2010; Novais \& Silva, 2011). Novais e Silva (2011, p. 11) entendem que, "como formação discursiva, a Nova História situa-se no interior da historiografia moderna e tem no diálogo com as ciências humanas um de seus componentes essenciais".

Nesse contexto, no qual Goff (2003) aponta que a história chega a correr o risco de perder-se como disciplina, diversas Ciências Sociais passaram a apropriar-se de elementos da história para se repensarem e a seus objetos, entre eles a Administração (Clark \& Rowlinson, 2004). Os diálogos mostraram-se um campo fértil para o desenvolvimento de novas perspectivas na área. Além disso, o questionamento sobre as pontes entre história e Administração, que vinham sendo estabelecidas pela business history, consolidou-se (Weatherbee, 2012).

Os estudos de business history passaram, então, a conviver com abordagens que radicalizam o uso da história, a fim de elaborar visões alternativas sobre o presente (Rowlinson et al., 2009). Rowlinson et al. (2009) indicam que perspectivas que centralizam o papel da história e da narrativa como fundamentos da construção de análises vêm ganhando espaço e fortalecendo a "virada histórica" na Administração (Clark \& Rowlinson, 2004; Rowlinson, 2013). A aproximação, já consolidada no exterior (Rowlinson, 2013) e em andamento no Brasil (e.g. Alcadipani \& Bertero, 2012; Vizeu, 2010), abre espaço para uma releitura do conhecimento produzido na área (Rowlinson et al., 2009; Üsdikem \& Kieser, 2004), valendo-se, por exemplo, da noção de que o campo é um campo de diálogos e interpretações em disputa para propor que se analise como os conceitos evoluíram no campo, utilizando a história conceitual (Matitz \& Vizeu, 2012).

Weatherbee (2012), entretanto, aponta que, em sua maioria, os estudos históricos na área permanecem utilizando história como sinônimo do passado, daquilo que efetivamente aconteceu, ou seja, a transição entre a cientificidade e a noção de narrativa identificada por Rowlinson et al. (2009) não é uma aproximação unívoca.

O emprego mais comum da história nos estudos administrativos e organizacionais segue uma lógica que assume a existência de um passado exterior que é descobrível, onde a "verdade" é encontrada por meio da correspondência de referenciais comuns entre os "fatos" e o passado - nos quais passado e história são sinônimos (Weatherbee, 2012, p. 205, tradução nossa, grifos no original).

Entendemos que as aproximações históricas serão lacunares, tentativas de se buscarem elementos para compreender o presente sem jamais esgotá-lo. As explicações totalizantes podem perder de vista matizes importantes nos processos de transformação sofridos pelas teorias ao longo do tempo e, ao concentrar-se nas grandes transformações, não conseguir captar o porquê de elas terem ocorrido ou como se desenrolaram. Ao mesmo tempo, de pouco adianta trazer elementos históricos para a análise do presente se eles não são tomados em sua complexidade e se é atribuída uma causalidade teleológica à história, como se o presente explicasse o que aconteceu no passado. 
A ideia de uma história unilinear e fonte de uma verdade acessível e universal pode ser repensada com base na noção de narrativas pontuais reunidas pelo historiador a fim de representar um ponto de vista sobre um objeto. Seguindo Guarinello (2004), entendemos que a história (europeia no que concerne à história do mundo e estadunidense no caso da Administração), que se quer universal, deve ceder espaço para as construções estabelecidas com base em objetos específicos, locais e do cotidiano de cada pesquisado, que, no seu conjunto, colaboram para uma história geral que, contudo, nunca será plenamente escrita.

Ao propor não apenas a história e o cotidiano, mas estudos de história do cotidiano como fundamento para a construção de novos olhares sobre a história na Administração, entendemos que tal transição tem potencial de permitir que narrativas que ficam à sombra das construções do centro saiam à luz. Pensar o cotidiano permite a elaboração de conhecimentos que sejam dissonantes daqueles que são hegemônicos, já que, ao contrário do que é geral, busca o que há de específico e abre espaço para o dia a dia das "pessoas comuns" e suas artes de fazer, que ganham a atenção da nova história (Matos, 2002).

Uma das formas privilegiadas de se articularem saberes locais contra a hegemonia da Administração de matiz estadunidense é a recuperação da história de como se desenvolveram as teorias localmente, bem como discutir as adaptações às quais foram sujeitados saberes "importados". Ao expor os processos específicos que permitiram a consolidação de certos discursos em detrimento de outros, bem como a forma específica de apropriação dos conceitos, seria possível ressaltar as singularidades das dinâmicas que acontecem localmente. Essa operação poderia ser elaborada, por exemplo, por meio da história dos conceitos (Matitz \& Vizeu, 2012) ou do trabalho histórico com atores institucionais importantes, como escolas (e.g. Alcadipani \& Bertero, 2012; Barros \& Carrieri, 2013) e associações de empresários (Zanetti \& Vargas, 2007), ou mesmo sujeitos praticantes, como os comerciantes que aprenderam intuitivamente a administrar no próprio fazer do seu ofício (Barros, Xavier, Cruz, Carrieri, \& Lima, 2012).

Todo o processo de criação e (re)produção do discurso efetiva-se no âmbito do fazer cotidiano das pessoas, muitas vezes no anonimato. Dessa forma, pesquisas que partem do cotidiano para narrar os modos de fazer e as concepções teóricas que vão tomando corpo podem ser de grande valia para o estabelecimento de um grupo contra-hegemônico de saberes situados localmente. Na próxima seção, nos aprofundaremos nessa discussão.

\section{DO UNIVERSAL AOS PARTICULARES: 0 COTIDIANO}

Assim como a história, a vida cotidiana tem sido utilizada como pano de fundo teórico, metodológico e epistemológico em diversas áreas de estudos, como a Filosofia, as Ciências Sociais, a Geografia, a História e as Ciências Sociais Aplicadas, entre elas a Administração. No que se refere ao tema do cotidiano, Chizzotti (2004) ressalta que autores como Agnes Heller, Henri Lefebvre e Michel de Certeau são os mais utilizados para se discutir esse tema no Brasil. Os estudos sobre o cotidiano tomam a experiência comum como ponto de partida para analisar fenômenos mais abrangentes, relacionando as tramas que ligam o dia a dia à transformação e reprodução de estruturas sociais (Guarinello, 2004). Nesse sentido, eles abrem espaço para que múltiplas visões sejam aceitas concomitantemente como parte da história, que pode ser protagonizada por pessoas comuns, em vez de olhar apenas os "grandes homens" (Certeau, 1994).

O cotidiano, contudo, é pouco trabalhado na Administração e também nos estudos organizacionais, embora haja exceções, como o trabalho de Oliveira e Cavedon (2013), sobre a micropolítica no cotidiano de um circo, e a investigação de Vargas e Junquilho (2013) sobre o fazer administrativo dos gestores. A partir de Certeau $(1994,1996)$, é possível não apenas analisar novos objetos de pesquisa na Administração, mas também lançar outros olhares sobre o que já é frequentemente estudado. Para Certeau (1994), estudar o cotidiano e enfatizar as ações dos sujeitos, bem como a criatividade e as formas de apropriação do real que emergem das múltiplas interações, permite uma reação à história única, representando uma reivindicação de espaço e um apelo à valorização da ação produzida no cotidiano por uma infinidade de sujeitos.

A valorização do cotidiano dá-se num contexto em que as diferenças regionais são, muitas vezes, ressaltadas, ainda que se atribua aos sujeitos uma só lógica de ação (Levigard \& Barbosa, 2010). A isso, contrapõe-se o fazer real dos indivíduos que encontram diversas soluções para seus problemas práticos, como discutido por Vargas e Junquilho (2013), ainda que tenham por ponto de partida para suas ações as lógicas dominantes da contemporaneidade, como observaram Oliveira e Cavedon (2013). A dominação absoluta das lógicas hegemônicas sobre todos os fazeres dos indivíduos exigiria aos sujeitos uma coerência que beira o impossível, abrindo-se, assim, possibilidades de se discutir o significado dessas incoerências, como formas de expressão criativa.

Segundo Guarinello (2004), o cotidiano é o momento em que o passado se liga ao futuro e no qual as estruturas sociais vivificam-se, exercem seus efeitos e são transformadas. 
O autor indica que, apesar de aparecer, à primeira vista, como um momento de mera reprodução das estruturas do passado, o cotidiano é o momento da mudança. Guarinello (2004) reitera que não há por que pensar história e cotidiano de maneira separada, como se a primeira fosse uma instância metafísica e ativa, ao passo que o segundo seria algo concreto, mas imutável. Para ele, o acontecimento histórico é sempre fruto do cotidiano.

No mesmo sentido, Duran (2007, p. 118) afirma que o cotidiano é "portador de uma historicidade que deve ser percebida com a preocupação investigativa de dar vozes a diversos sujeitos históricos elaborando a construção e desconstrução da história, partindo de novas fontes e de novos objetos". O cotidiano permite, assim, identificar como as grandes estruturas impactam o dia a dia das pessoas, mas também como elas se valem de pequenas astúcias (Certeau 1994) para resistir à dominação e, mesmo, provocar transformações.

No cotidiano "é necessário que atividades, pensamentos, e ações dos indivíduos sejam espontâneos [...], pois senão se tornaria inviável a produção e reprodução da sua existência social” (Rossler, 2004, p. 106). Por isso, Rossler (2004, p. 107) entende que, na "vida cotidiana, os pensamentos e as ações são muito mais determinados por sua funcionalidade [...] imediata do que por razões de ordem teórica ou filosófica". Nesse processo, as ações cotidianas estão constantemente em mutação, já que "saber algo significa que o sujeito particular se apropria dos conteúdos de seu meio, incorpora neles sua própria experiência, conseguindo realizar, assim, tipos heterogêneos de ações cotidianas" (Caldeira, 1995, p. 7).

O estudo do cotidiano é, então, conforme Duran (2007), muitas vezes contraditório à ideia de que a razão e a racionalidade são o substrato único da ação humana. É no cotidiano que emergem: “'artes de fazer', 'astúcias sutis', 'táticas de resistência' que alterariam os objetos e os códigos, e estabelecendo uma (re)apropriação do espaço e do uso ao jeito de cada um" (Duran, 2007, p. 118). Mesmo quando aparentam ser mera reprodução, as ações do cotidiano podem ser reinventadas e reapropriadas num sentido transgressor das normas vigentes (Oliveira \& Cavedon, 2013).

Dessa forma, no cotidiano, os sujeitos são chamados a reproduzir o conjunto de sistemas hegemônicos que os subjuga. Ao mesmo tempo, têm espaço para as pequenas subversões das regras, seja para afrontar os poderes estabelecidos ou para ampliar seu conforto com as ações desempenhadas (Certeau, 1994). Pesquisar sobre o cotidiano não é ignorar os fatores com impactos nos grandes conjuntos, mas tentar percebê-los com base na discussão sobre o detalhe. Cabe ainda ressaltar, em conformidade com Certeau (1994, p. 143):
O saber fazer das práticas cotidianas não seria conhecido senão pelo intérprete que o esclarece no seu espelho discursivo, mas que não o possui tampouco. Portanto, não pertence a ninguém. Fica circulando entre a inconsciência dos praticantes e a reflexão dos não praticantes, sem pertencer a nenhum. Trata-se de um saber anônimo e referencial, uma condição de possibilidades das práticas técnicas ou eruditas.

A ação do sujeito é sempre um novo desafio ao poder estabelecido, pois colocará em desenvolvimento algo novo, ainda que o indivíduo não tenha intentado estabelecer qualquer tipo de afronta às disciplinas que o regulam (Souza, 2002). Isso porque o agir sempre é portador do novo, e o cotidiano não permite a repetição eterna, já que o sujeito e o contexto da ação estão constantemente em transformação, a partir da interação com as forças que o cercam.

0 presente que não é mera repetição do passado, mas um campo de restrições e possibilidades em aberto para projetos alternativos de futuro. 0 presente, entendido como o dia de hoje, é como o vértice de uma tríade temporal que forma, com passado e futuro, o curso da história (Guarinello, 2004, p. 26).

Estudar o cotidiano permite, assim, analisar a riqueza das ações dos sujeitos que são, muitas vezes, esquecidos pelas teorias sociais (Martins, 2008), incluídas as administrativas. Cabem, além do pequeno "capitalista”, as ações dos funcionários de uma lojinha ou de quaisquer grupos de sujeitos esquecidos, como os mascates, caixeiros e tropeiros (Barros et al., 2012), que têm no cotidiano o seu espaço de fazer e reflexão, no qual produzem e reproduzem o conjunto da realidade social.

Além dos estudos da realidade dos indivíduos isoladamente, intentamos provocar os pesquisadores da Administração a buscar compreender as estruturas sociais e o contexto específico no qual as ações se realizam, com base em pesquisas que tomem como objeto o cotidiano. Para isso, contudo, é necessário ir além do anedotário (Guarinello, 2004), ao mesmo tempo que se dá peso à atuação dos sujeitos. Não "um indivíduo abstrato ou excepcional, mas sim o indivíduo da vida cotidiana, isto é, o indivíduo voltado para as atividades necessárias à sua sobrevivência” (Patto, 2013, p. 124). Conforme Caldeira, "cotidiano e história se interpenetram e, dessa forma, pode-se compreender que o conteúdo social presente nas atividades co- 
tidianas não é arbitrário e que o cotidiano reflete e antecipa a história" (Caldeira, 1995, p. 7).

Para Gomes e Santana (2013), a história oral é a técnica mais adequada para se resgatar o cotidiano das pessoas anônimas a fim de reconstruir a rotina de pequenas firmas ou de ramos de negócios que se perderam ou são marginais na economia. A história oral, bem como o uso de arquivos pessoais, charges e jornais, permitiria aos estudos em Administração revisar a participação dos diversos atores na construção das organizações, sem permanecer privilegiando apenas aqueles que, pela posição de poder que ocupam, têm mais capacidade de fazer suas narrativas ficarem registradas.

A História Oral tem condições de recuperar a visão das pessoas comuns dentro das empresas os trabalhadores e operários - trazendo à tona as "memórias subterrâneas" de grupos excluídos do processo decisório, que, de outra forma, não seriam consideradas nem fariam parte da História (Gomes \& Santana, 2013, p. 14).

Partindo do uso da história oral, mas também de outras fontes, como arquivos pessoais, vídeos ou charges, é possível, assim, recontar as experiências microscópicas dos sujeitos que contribuem para a construção das organizações. Por outro lado, é possível trocar a ênfase dos grandes negócios pelo cotidiano do trabalhador formal ou informal e pelas experiências de pequenos negociantes em empresas familiares ou não, formais e informais (Barros et al., 2012; Martins, 2008).

Se, como apontam Gomes e Santana, o "corriqueiro, o cotidiano da administração de empresas ainda é negligenciado" (Gomes \& Santana, 2010, p. 11), é possível afirmar que a construção das narrativas históricas sobre a administração no Brasil ainda é tímida e não reflete as especificidades do estabelecimento desses conhecimentos no País - com algumas exceções, como o trabalho de Curado (2001), que analisa o estabelecimento das práticas administrativas no Brasil, e o trabalho de Zanetti e Vargas (2007) sobre a apropriação dos discursos administrativos pelo empresariado nacional nas primeiras décadas do século XX.

Acreditamos, assim, que, se estudadas as "artes de fazer" de pessoas cuja participação para a formação da sociedade foi (e continua sendo) pouco analisada (Certeau, 1994), seria possivel conhecer melhor as especificidades do desenvolvimento da Administração em âmbito local. Ao mesmo tempo, abrir-se-ia espaço para entender as diferenças em relação às experiências dos países centrais que recorrentemente são usadas de modelo para guiar a ação dos administradores locais.
Surge, assim, uma alternativa à história (da Administração) tradicional, na qual as experiências dessas pessoas são excluídas. É aberto espaço para o foco nos praticantes da "gestão ordinária” e em seus modos de apropriação, produção e reprodução da Administração em âmbito local, ao longo do tempo, como discutido, por exemplo, por Frenkel e Shenhav (2006).

Os estudos de história do cotidiano permitem o foco na especificidade, como verificar o efeito de "grandes transformações" - a vinda de indústrias automotivas para o Brasil, por exemplo - na rotina das pessoas implicadas nos processos. Aliás, o efeito desses "grandes eventos" nos indivíduos e como significados e reações são construídos podem ser elementos estruturados de uma nova narrativa do acontecimento e da construção dos conhecimentos.

Para Carvalho (2006), bem como para Holanda (2011), as práticas administrativas são diversas, o que também pode ser mais bem compreendido se analisadas as minúcias que orientam a ação das diversas pessoas que exercem a Administração. A autora aponta, por exemplo, que algumas pessoas exercem a gestão de suas organizações pautadas na preservação de modos de fazer e agir, como que mantendo uma tradição.

Não é apenas a teoria da Administração que precisa estar permanentemente aberta, mas também o olhar do pesquisador, percebendo que a realidade é sempre mais complexa. Ela se constrói cotidianamente, ao longo do tempo e de modo diferente do que foi ou é narrado nos esquemas interpretativos dominantes, ainda que tenham relação com as múltiplas instâncias de produção de discursos interpretativos sobre o fazer, que vão desde o meio acadêmico, passando pelas revistas de negócio, até as vivências em família de cada sujeito que aciona os conhecimentos que possuí, incluindo os saberes práticos. 0 alijamento daquilo que é específico no pensamento administrativo foi ressaltado por Ibarra-Colado (2006), que pede por um estranhamento epistemológico em vez da reprodução irrefletida de conhecimentos e práticas produzidos alhures.

\section{CONSIDERAÇÕES FINAIS}

Como viemos discutindo, as construções elaboradas nos países centrais, especialmente nos Estados Unidos, têm lugar de proeminência na Administração. Mesmo com a inserção da perspectiva histórica, muitas vezes os estudos realizados com objetos ou com base em teorias não hegemônicas permanecem marginais, sendo a história da disciplina narrada a partir do ponto de vista dos EUA.

Diversos estudos buscam, contudo, contrapor-se à ideia de que a Administração é um corpo de práticas e saberes uni- 
versalizável. Pesquisadores como Alcadipani et al. (2012), Faria, Ibarra-Colado e Guedes (2010), Cooke (2010), Ibarra-Colado (2006) e Chanlat (2000) têm questionado as "conversações anglo-saxônicas". Para esses autores, é preciso discutir a colonização dos saberes locais e fomentar o pluralismo, inibindo discursos homogeneizantes. A realidade da Administração é diversa, podendo ser estudada no cotidiano das pessoas, nas estratégias e práticas de sobrevivência utilizadas no dia a dia. Também é possível lançar luzes sobre a gestão ordinária, realizada cotidiana e despretensiosamente por diversos sujeitos anônimos.

A Administração como Ciência Social Aplicada busca estabelecer um conhecimento denominado moderno, em acordo com a racionalidade instrumental, voltada para o cálculo entre meios e fins, deixando de lado outras formas de administrar e agir no cotidiano. Na visão de Benjamin (2006), podemos dizer que a razão instrumental é a derrocada das outras razões. A razão instrumental é típica do capitalismo, pois é uma racionalidade que se volta para o aprimoramento da técnica e para o aumento da produtividade.

O conhecimento administrativo baseado na razão instrumental, na ideia de progresso interminável, do aperfeiçoamento técnico das ferramentas e modelos trazidos na/pela modernidade, busca reforçar uma temporalidade que leva a um sentimento de que tudo se torna transitório. Para Gagnebin (2004, p. 50), com base em Benjamin: "esta compreensão da temporalidade é inseparável da produção capitalista, em particular do seccionamento do tempo no trabalho industrial e da transformação dos produtos da atividade humana em mercadorias, novidades sempre prestes a se transformarem em sucata".

Os fazeres cotidianos situados historicamente podem constituir-se como uma forma de questionar essa lógica que permeia boa parte das construções sobre Administração, colocando em questão a ascendência da racionalidade instrumental sobre as outras formas construídas na sociedade (Benjamin, 2006; Ramos, 1981). Outro ponto importante e já mencionado neste trabalho é pensarmos no que Alcadipani e Rosa (2010) propõem, acerca da importância de descolonizar o olhar do pesquisador e assumir uma postura crítica diante do conhecimento calcado na suposta segurança epistemológica advinda da mimetização dos padrões das ciências naturais. Nesse sentido, é importante reconhecer a alteridade não só do conhecimento mas também do pesquisador e de cada um dos sujeitos e objetos de pesquisas.

É necessário estar atento aos diversos mecanismos de conformação do saber aos quais os pesquisadores também se submetem. 0 imperativo por publicações em revistas com as maiores qualificações nos sistemas de qualificação, como o
Qualis/ Capes, deve ser considerado concomitantemente aos padrões impostos por essas revistas, especialmente a conformidade a um certo tipo de conhecimento. Além disso, no que concerne às revistas estrangeiras que dominam o topo do Qualis Capes, não se pode ignorar a demanda, por vezes implícita e insuperável, de se exigir que o autor tenha o inglês como primeira língua.

Como Santos (2006), concordamos que há conhecimentos heterogêneos que devem ser admitidos, conhecimentos tidos como vulgares, práticos. Conhecimentos com base no cotidiano e historicamente situados, pelos quais os sujeitos de pesquisa orientam suas ações, dão sentido às suas vidas e às de suas famílias. Conhecimentos que podem dialogar com a ciência, criando oportunidades de novos saberes, fazendo, assim, com que o saber administrativo hegemônico, de origem estadunidense, reconheça outros saberes e, por consequência, sua falibilidade e seu paroquialismo.

Nesse sentido, a gestão ordinária pode ser entendida como aquela que não está pautada e não internaliza (ou internaliza apenas em parte) os princípios de desempenho e disciplina, a racionalidade instrumental, os papeis predefinidos de produtor/empreendedor, útil para a sociedade e a separação do trabalho/negócio/família. A gestão ordinária pode dar oportunidade ao pesquisador/professor de gestão para observar as intencionalidades institucionais e de grupos sociais em conduzir um acordo implícito e objetivo da não incorporação do valor humano nas práticas sociais. Narrar os desenvolvimentos cotidianos dos protagonistas dessa gestão marginalizada contribuiria para reposicionar seu status diante dos saberes legitimados.

Evidenciar uma gestão ordinária, outra gestão (Alcadipani \& Rosa, 2010; Barros, Cruz, Xavier, Carrieri, \& Lima, 2011; Holanda, 2011; Ibarra-Colado, 2006), não é negar a Administração como um saber-poder. É questioná-la, buscando abrir o termo a uma reutilização e uma redistribuição que anteriormente não estava autorizada. Desconstruir a noção de que exista uma Administração unitária é possibilitar múltiplas significações, buscando emancipá-la das ontologias às quais está/esteve restrita e transformá-la em um espaço que permita que novos significados possam emergir.

Em certo sentido, propomos que se reveja a postura naturalizada diante da dominação das formas americanizadas de administrar, em geral tidas como portadoras de conteúdos neutros e normatizados. Desconstruir o termo e seus usos, com a inserção de novas perspectivas e abordagens no nosso horizonte de reflexão, é deslocá-los dos contextos dominantes nos quais foram dispostos como instrumentos de poder, e, inclusi- 
ve, colocar em análise nossa prática de ensino, de coordenação e participação de grupos de pesquisa, nossos lugares de saber-poder, analisando em que medida não contribuímos para a reprodução de um saber que exclui o “outro", habitante das margens do capitalismo, nós mesmos.

\section{NOTA DOS AUTORES}

Este trabalho foi construído tendo por base um diálogo entre as ideias desenvolvidas nas teses de doutorado e de livre docência dos autores.

\section{REFERÊNCIAS}

Alcadipani, R, \& Bertero, C. O. (2012). Guerra Fria e ensino do management no Brasil: o caso da FGV-EAESP. RAE-Revista de Administração de Empresas, 52(3), 284-299.

Alcadipani, R, Khan, F. R, Gantman, E, \& Nkomo, S. (2012). Southern voices in management and organization knowledge. Organization, 19(2), 131-143.

Alcadipani, R, \& Rosa, A. R. (2010). O pesquisador como o outro: uma leitura pós-colonial do "borat” brasileiro. RAE-Revista de Administração de Empresas, 50(4), 371-382.

Alcadipani, R, \& Rosa, A. R. (2011). From grobal management to glocal management: Latin American perspectives as a counter-dominant management epistemology. Canadian Journal of the Administrative Sciences, 28(4), 453-466.

Barley, S, \& Kunda, G. (1992). Design and devotion: surges of rational and normative ideologies of control in managerial discourse. Administrative Science Quarterly, 37(3), 363-399.

Barros, A, \& Carrieri, A. (2013). Ensino superior em administração entre os anos 1940 e 1950: uma discussão a partir dos acordos de cooperação Brasil-Estados Unidos. Cadernos Ebape.br, 11(2), 256-273.

Barros, A, Cruz, R. C, Xavier, W, Carrieri, A, \& Lima, G. (2011). Apropriação dos saberes administrativos: um olhar alternativo sobre o desenvolvimento da área. RAM-Revista de Administração Mackenzie, 12 (5), 43-67.

Barros, A, Xavier, W, Cruz, R, Carrieri, A, \& Lima, G. (2012). O ethos capitalista weberiano e a afetividade no comércio mineiro. Cadernos Ebape. br, 10(2), 376-392.

Benjamin, W. (2006). Passagens. Belo Horizonte, São Paulo: UFMG/Imprensa Oficial do Estado de São Paulo.

Burke, P. (1992). A escrita da história. São Paulo: Editora da Unesp.

Burke, P. (2010). A escola dos annales 1929-1989 (2a ed.). São Paulo: Editora da Unesp.

Caldeira, A. M. (1995). A apropriação e construção do saber docente e a prática cotidiana. Cad. Pesqui., (95), 5-12.

Candiotto, C. (2010). Foucault e a crítica da verdade. Belo Horizonte: Autêntica; Curitiba: Champagnat.
Carvalho, C. A. P. (2006). Outras formas organizacionais: o estudo de alternativas ao modelo empresarial na realidade brasileira. Porto Alegre. Projeto Procad/CNPq.

Certeau, M. (1994). A invenção do cotidiano I: as artes do fazer. Petrópolis: Vozes.

Certeau, M. (1996). A invenção do cotidiano 2: morar, cozinhar. Petrópolis: Vozes.

Chanlat, J-F. (2000). Ciências sociais e management: reconciliando o econômico e o social. São Paulo: Atlas.

Chizzotti, A. (2004). Pesquisa em ciências humanas e sociais. São Paulo: Cortez.

Clark, P, \& Rowlinson, M. (2004). The treatment of history in organization studies: towards an 'historic turn'? Business History, 46(3), 331-352.

Clegg, S. R, \& Hardy, C. (1996). Introduction: organizations, organization and organizing. In S. R. Clegg, C. Hardy, \& W. Nord (Eds) Handbook of organization studies (pp. 1-28). London: Sage.

Cooke, B. (2010). Managerialism as knowing and making Latin America: International development management and world bank interventions. In Faria, A.; GUEDES, A. (eds.), International Management and International Relations a Critical Perspective from Latin America (pp. 161-184). London: Routledge.

Curado, I. (2001). O desenvolvimento dos saberes administrativos em São Paulo. Tese de doutorado, Administração, Escola de Administração de Empresas de São Paulo, Fundação Getulio Vargas, São Paulo.

Duran, M. C. (2007). Maneiras de pensar o cotidiano com Michel de Certeau. Diálogo Educacional., 7(22), 115-128.

Faria, A, Ibarra-Colado, E, \& Guedes, A. L. (2010). Internationalization of management, neoliberalism and the Latin America challenge. Critical perspectives on international business, 6(2-3), 97-115.

Foucault, M. (1987). Vigiar e punir: nascimento da prisão. Petrópolis: Vozes.

Foucault, M. (2009). A arqueologia do saber (7a ed.). Rio de Janeiro: Forense Universitária.

Frenklel, M. (2009). The Americanization of the antimanagerialist alternative in Israel: how foreign experts retheorized and disarmed workers' participation in management, 1950-1970. International Studies of Management and Organization, 38(4), 17-37.

Frenkel, M, \& Shenhav, Y. (2003). From Americanization to colonization: the diffusion of productivity models revisited. Organization Studies, 24(9), 1537-1561.

Frenkel, M, \& Shenhav, Y. (2006). From binarism back to hibridity: a postcolonial reading of management and organization studies. Organization Studies, 27(6), 855-876.

Gagnebin, J-M. (2004). História e narração em Walter Benjamin (2a ed.). São Paulo: Perspectiva.

Ginzburg, C. (1989). O queijo e os vermes: o cotidiano e as ideias de um moleiro perseguido pela Inquisição. São Paulo: Cia. das Letras.

Goff, J, Le. (2003). História e memória (5a ed.). Campinas: Editora da Unicamp.

Gomes, A, \& Santana, W. (2010). A história oral na análise organizacional: a possível e promissora conversa entre a história e a administração. Cadernos Ebape, 8(1), 1-18.

Grant, J. D, \& Mills, A. J. (2006). The quiet Americans: formative context, the Academy of Management leadership, and the management textbook, 1936-1960. Management \& Organizational History, 1(2), 201-224. 
Grey, C. (2010). Organizing studies: publications, politics and polemic. Organization Studies, 31(6), 677-694.

Guarinello, N. (2004). História científica, história contemporânea e história cotidiana. Revista Brasileira de História, 24(48), 13-38.

Holanda, L. A. (2011). Resistência e apropriação de práticas de management no organizar de coletivos da cultura popular. Tese de doutorado, Administração, Propad/UFPE, Recife.

Ibarra-Colado, E. (2006). Organization studies and epistemic coloniality in Latin America: thinking otherness from the margins. Organization, 13(4), 463-488.

Jacques, R. (1996). Manufacturing the employee. London: Sage Publications.

Kelley, E. S, Mills, A. J, \& Cooke, B. (2009). Management as a Cold War phenomenon? Human Relations, 59(5), 603-610.

Levigard, Y, \& Barbosa, R. (2010). Incertezas e cotidiano: uma breve reflexão. Arquivos Brasileiros de Psicologia, 62(1), 84-89.

Locke, R. (1996). The collapse of the American management mystique. Oxford: Oxford University Press.

Martins, J. S. (2008). A sociabilidade do homem simples. São Paulo: Hucitec.

Matitz, Q. R. S, \& Vizeu, F. (2012). Construção e uso de conceitos em estudos organizacionais: por uma perspectiva social e histórica. RAPRevista de Administração Pública, 46(2), 577-598.

Matos, M. (2002). Cotidiano e cultura: história, cidade e trabalho. Bauru, SP: EDUSC.

Mattos, P. L. (2009). “Administração é ciência ou arte?” O que podemos aprender com este mal-entendido? RAE-Revista de Administração de Empresas, 49(3), 349-360.

Meyer, R, \& Boxenbaum, E. (2010). Exploring European-ness in organization research. Organization Studies, 31(6), 737-755.

Mignolo, W. (2007). Delinking. Cultural Studies, 21(2-3), 449-514.

Murphy, J, \& Zhu, J. (2012). Neo-colonialism in the academy? AngloAmerican domination in management journals. Organization, 19(6), 915-927.

Novais, F. A, \& Silva, R. (2011). Introdução: para a historiografia da nova história. In F. A. Novais, \& R. Silva (Orgs.). Nova história em perspectiva. (Vol. 1, pp. 6-73). São Paulo: Cosac Naify.

Oliveira, J, \& Cavedon, N. R. (2013). Micropolíticas das práticas cotidianas: etnografando uma organização circense. RAE-Revista de Administração de Empresas, 53(2), 156-168.

Patto, M. (1993). O conceito de cotidianidade em Agnes Heller e a pesquisa em educação. Perspectivas, 16, 119-141.
Pfeffer, J. (1993). Barriers to the advance of organization science: paradigm development as a development variable. The Academy of Management Review, 18(4), 599-620.

Ramos, A. G. (1981). A nova ciência das organizações: uma reconstrução da riqueza das nações. Rio de Janeiro: Editora da FGV.

Rossler, J. H. (2004, abril). O desenvolvimento do psiquismo na vida cotidiana: aproximações entre a psicologia de Alexis N. Leontiev e a teoria da vida cotidiana de Agnes Heller. Caderno Cedes, 24(62), 100116.

Rowlinson, M. (2013). Management \& organizational history: the continuing historic turn. Management \& Organizational History, 8(4), 327-328.

Rowlinson, M, Jacques, R, \& Booth, C. (2009). Critical management and organizational history. In M. Alvesson, T. Bridgman, \& H. Willmott (Eds.). The Oxford handbook of critical management studies (pp. 286-304). Oxford: Oxford University Press.

Runté, M, \& Mills, A. J. (2006). Cold War, chilly climate: exploring the roots of gendered discourse in organization and management theory. Human Relations, 59(5), 695-720.

Said, E. (1990). Orientalismo: o Oriente como invenção do Ocidente. São Paulo: Cia. das Letras.

Santos, M. (2006). A natureza do espaço: técnica e tempo: razão e emoção (4a ed.). São Paulo: Edusp.

Souza, A, Filho. (2002). Michel de Certeau: fundamentos de uma sociologia do cotidiano. Sociabilidades (USP), 2, 129-134.

Üsdikem, B, \& Kieser, A. (2004). Introduction: history in organisation studies. Business History, 46(3), 321-330.

Vargas, R. A, \& Junquilho, G. S. (2013). Funções administrativas ou práticas? As "artes do fazer" gestão na Escola Mirante. Revista de Ciências da Administração, 15(35), 180-195.

Vizeu, F. (2010). Potencialidades da análise histórica nos estudos organizacionais brasileiros. RAE-Revista de Administração de Empresas, 50(1), 37-47.

Weatherbee, T. (2012). Caution! This historiography makes wide turns: historic turns and breaks in management and organization studies. Management \& Organizational History, 7(3), 203-218.

Xavier, W, Barros, A, Cruz, R, Carrieri, A. (2012). O imaginário dos mascates e caixeiros-viajantes de Minas Gerais na formação do lugar, do não lugar e do entrelugar. Revista de Administração, 47(1), 38-50.

Zanetti, A, \& Vargas, J. T. (2007). Taylorismo e fordismo na indústria paulista: o empresariado e os projetos de organização racional do trabalho, 1920 - 1940. São Paulo: Associação Editorial Humanista. 